\title{
Netwerkvorming door certificatie als onderdeel van Europese industriepolitiek
}

\author{
Dr. Mr. N.M. Wijnberg en Dis. V.C. de Graaff
}

\section{Inleiding}

Zowel netwerkvorming als certificatie is een onderwerp waarvoor grote aandacht bestaat, zowel in de wetenschap als in de praktijk van het bedrijfsleven. De relaties tussen beide onderwerpen zijn eerder bestudeerd en afzonderlijk zijn beide onderwerpen ook in verband gebracht met internationale handel. In dit artikel zal getoond worden hoe juist de combinatie van een uitgebreidere vorm van certificatie en netwerkvorming tot een systematische verandering leidt die de positie van de betrokken landen op het terrein van de internationale handel gunstig kan beïnvloeden.

Wanneer beleidsmakers trachten de prestaties van industrieën en diensten op de internationale markt te verbeteren, doen zij vaak enerzijds een poging zich te beschermen tegen invoer uit de meest succesvolle landen en anderzijds een poging tot imitatie van dat wat in die andere landen kennelijk succesvol is. Wat de Europese Gemeenschap betreft kwam dit aanvankelijk vooral neer op het zich zo goed mogelijk beschermen tegen, en navolgen van, het Amerikaanse voorbeeld. In de laatste jaren heeft Japan deze vijand- en voorbeeldfuncties overgenomen.

Het Japanse succes wordt aan vele factoren toegeschreven. Centraal in elke opsomming staan de beschermde thuismarkt, de actief interveniërende overheid, vooral in de vorm van het ministerie

Dr. Mr. N.M. Wijnberg is universitair Hoofddocent Technologiebeleid, Erasmus Universiteit Rotterdam, Faculteit der Bedrijfskunde en universitair Docent Europese Studies, Universiteit van Amsterdam, Faculteit der Letteren.

Drs. V.C. de Graaff is Assistent in Opleiding, Erasmus Universiteit Rotterdam, Faculteit der Bedrijfskunde, Vakgroep Management van Technologie en Innovatie. voor buitenlandse handel en industrie (MITI), de nadruk op kwaliteit en daarbij behorende managementtechnieken (quality circles etc.), (proces-) innovatie, en de nauwe samenwerkingsverbanden tussen grote groepen bedrijven (Keiretsu) die echter hevige concurrentie niet lijken weg te nemen, op de thuismarkt noch op de wereldmarkt.

Als reactie op het Japanse succes zijn in de EEG op dit moment zowel defensieve als offensieve/imitatieve acties te herkennen. Onder offensief bedoelde acties vallen het selectief minder streng toepassen van de mededingingsregels om het bedrijven mogelijk te maken door samenwerking of samengaan een sterkere positie op de wereldmarkt te verwerven, en de innovatieprogramma's als ESPRIT en BRITE. Defensieve acties zijn het onderhandelen van zogenaamde Voluntary Export Restraints met betrekking tot bijvoorbeeld auto's, en het tegenhouden van goedkope importgoederen op grond van vermeende 'dumping', bijvoorbeeld in het geval van kopieermachines. Europese beleidsmakers verwachten zowel in offensieve als in defensieve zin positieve resultaten van het nastreven van pan-Europese technische normen en kwaliteitseisen. Certificatie makt van dit beleid eveneens een belangrijk onderdeel uit.

Deze rol kan nog versterkt worden. De huidige defensieve en offensieve beleidsmaatregelen staan bloot aan veel kritiek. Het imiteren van geïsoleerde elementen van het Japanse industriële systeem, bijvoorbeeld industriepolitiek a la MITI of quality circles, lijkt veel minder resultaten af te werpen dan gehoopt. Ook het, volgens Japans model, integreren van Just-in-Time (JIT) en Total Quality Management (TQM) systemen in ketens van toeleveranciers leidde tot sterk tegenvallende resultaten (Turnbull. Oliver \& Wilkinson. 1992). Dit wordt veroorzaakt doordat de geïmiteerde 
elementen onderling samenhangen en slechts tot hun recht komen in het volledige systeem.

De stelling die hier wordt verdedigd is dat certificatie een middel kan zijn voor de EEG om een equivalent systeem op te bouwen, vooral als er op grotere schaal aandacht wordt gegeven aan het toevoegen van verbeternormen aan het certificaat, hetgeen zinvoller is dan het nabootsen van losse elementen uit andermans systeem (Wijnberg, 1994). Om deze stelling te onderbouwen wordt allereerst kort certificatie omschreven. Vervolgens zal kort aandacht worden besteed aan juist die onderlinge samenhang van de elementen uit het Japanse systeem en de centrale plaats van netwerken, de Keiretsu, hierin. Daaropvolgend zal een beeld geschetst worden hoe certificatie kan bijdragen tot het ontstaan van een economisch systeem in Europa dat de door de Japanners bereikte resultaten op een eigen wijze kan nastreven. Enkele praktijkvoorbeelden zullen worden gegeven van grote Europese bedrijven die in toenemende mate certificatie gebruiken in hun relaties met hun toeleveranciers.

\section{Certificatie}

Certificatie is gedefinieerd als het geheel van activiteiten op grond waarvan een onafhankelijke, deskundige en betrouwbare instelling schriftelijk kenbaar maakt dat een gerechtvaardigd vertrouwen bestaat dat een duidelijk omschreven onderwerp van certificatie voldoet aan voorafgestelde eisen. Naast systeemcertificaten kunnen produkt-, diensten-, proces- en vakbekwaamheidcertificaten onderscheiden worden. Certificaten vervullen verschillende functies. Publieke certificatie, verplicht dan wel vrijwillig, is op te delen naar certificatie voor twee doelen. Ten eerste certificatie gericht op het slechten van handelsbarrières. Ten tweede certificatie met als doel een minimaal niveau te bewerkstelligen t.a.v. risico's verbonden aan veiligheids-, gezondheids- en milieu-aspecten.

Private certificatie heeft als voornaamste functie het verschaffen van informatie tussen marktpartijen en het daarmee transparanter maken van de markt en het verlagen van transactiekosten. De overheid en ook marktpartijen verwachten echter ook vaak dat private certificatie zal leiden tot het verhogen van de gemiddelde kwaliteit van goederen en diensten. Opgemerkt moet worden dat de huidige ISO 9000 normen slechts aanleiding kunnen vormen voor aanpassingen binnen het huidige kader. Van der Bij (1992) merkt dan ook terecht op dat de ISO 9000 normen vooral geschikt zijn voor organisaties die, in de terminologie van Mintzberg, als 'machine bureaucracies' te omschrijven zijn. Om verdergaande verbetering en vernieuwing te bereiken zijn zowel flexibelere organisaties als andersoortige normen gewenst. Zoals in het vervolg zal blijken, wordt verwacht dat de door certificatie geregulariseerde kwaliteitszorg de basis zal kunnen vormen van de ontwikkeling van voor de Europese economie gunstige netwerken of samenwerkingsverbanden. Het is duidelijk dat certificatie van toeleveranciers kan bijdragen aan het vertrouwen dat industriële afnemers in die toeleveranciers hebben. Clusters van toeleveranciers en afnemers kunnen ontstaan die gelijksoortige en gelijkwaardige normen hanteren. Ook wordt door certificatie het ontstaan van lange-termijnrelaties bevorderd, die ook nauwere sturing, en eventueel technologische bijstand. van de zakelijke partners onderling mogelijk maken. Vooral het invoeren van verbeternormen in certificatie, bijv. inhoudend dat kwaliteitsnormen ieder jaar met een bepaald percentage verhoogd dienen te worden, zou aan deze laatstgenoemde ontwikkeling kunnen bijdragen.

\section{Het Japanse economische systeem}

In de naoorlogse periode heeft Japan de meest opvallende groeicijfers getoond. Naast deze stormachtige groei van de binnenlandse economie had Japan ook vrijwel continu een groot overschot op haar handelsbalans. Vooral in de tachtiger jaren leek het alsof Japanse bedrijven onverslaanbaar waren op alle markten die zij binnengingen (van Wolferen, 1989).

Het beeld ontstond van een vooruitziende en efficiënte bureaucratie die op basis van een analyse van levenscyclussen van produkten en industrieën (Rapp, 1992) het Japanse bedrijfsleven de weg wees naar de meest belovende markten, de bedrijven kredieten verstrekte en samenwerkingsverbanden organiseerde.

De bedrijven leken, vergeleken met hun westerse concurrenten, met lange-termijnplannen te werken, gemakkelijker diepte-investeringen te doen in kwaliteit en innovatie en marktaandeel belangrijker te kunnen vinden dan winstmarges. Deze bedrijven waren naar westerse maatstaven zelden bijzonder groot maar zij bleken zich vaak te bevinden in netwerken van toeleveranciers, afnemers, banken en verzekeraars: de Keiretsu, 
die naar ons oordeel een kernonderdeel van het Japanse systeem vormen. De verschillende bedrijven in een Keiretsu gaan enerzijds lange-termijncontracten met elkaar aan, anderzijds leggen zij elkaar ook hoge prestatienormen op, hetgeen des te makkelijker is dankzij de intensieve en langdurige contacten die inzicht verschaffen over de capabiliteiten van de ander (Imai, 1989).

Een leverancier van een bepaald onderdeel kan een contract voor vijf of tien jaar krijgen van een fabrikant maar die zal niet slechts een scherpe prijs bedingen maar ook bijvoorbeeld vastleggen dat die prijs elk jaar 5\% daalt omdat de fabrikant verwacht dat de toeleverancier elk jaar door learning-by-doing en/of procesinnovatie minstens $5 \%$ kan besparen. Lukt dit niet dan springt de fabrikant eventueel zelf in teneinde de doelstellingen alsnog te bereiken (Asanuma, 1989). De lange-termijnrelaties binnen de Keiretsu maken het makkelijker lange-termijninvesteringen te plegen in innovatie en kwaliteit.

Voor westerse bedrijven is het relatief moeilijk zich op de Japanse (industriële) markten te begeven als zij niet bereid of in staat zijn zich als een lange-termijnpartner te profileren en zich zo in een Keiretsu-netwerk in te dringen. Zo dragen de Keiretsu bij tot het afsluiten van de Japanse markt voor buitenlandse bedrijven. De Keiretsu maakt overheidssturing van de economie ook eenvoudiger omdat de overheid slechts met de centrale bedrijven in de Keiretsu hoeft te werken om grote segmenten van de economie in de gewenste richting te sturen.

Hoewel de Japanse overheid een weinig streng mededingingsbeleid voert (Cutts, 1992) en hoewel zoals vermeld de binnenlandse markt relatief beschermd is, maakt enerzijds de druk van de overheid op de bedrijven om te exporteren en anderzijds de behoefte van de bedrijven zelf om vooral marktaandeel te vergroten dat de Japanse bedrijven voortdurend blootgesteld blijven aan gezonde concurrentiedruk van bedrijven uit andere Keiretsu en buitenlandse bedrijven wier thuismarkten veroverd moeten worden.

Het is echter een misverstand te menen dat dezelfde resultaten in Europa bereikt kunnen worden door een exportbevorderend industriebeleid en het aanmoedigen van samenwerking tussen bedrijven, onder andere door het verslappen van de toepassing van het EEG mededingingsrecht. Het Japanse systeem, en de specifieke netwerken die daarin een centrale rol spelen, heeft zich onder andere zo kunnen ontwikkelen door een geheel eigenaardige kapitaalmarkt die in Europa niet eenvoudig te imiteren lijkt.

Voor de tweede wereldoorlog werd de Japanse economie beheerst door grote sterk verticaal geïntegreerde familie-ondernemingen: Zaibatsu. De Amerikaanse bezettingsmacht weet het Japanse militarisme ten dele aan de activiteiten van deze machtige Zaibatsu die opgesplitst werden. De aandelen van de daaruit ontstane ondernemingen werden op de beurs van Tokyo verkocht.

Additionele regelgeving bepaalde dat geen bedrijf zijn eigen aandelen mocht terugkopen, dat geen bedrijf aandelen mocht bezitten met een grotere waarde dan het verdere eigen vermogen, en dat banken niet meer dan 5\% mochten bezitten van de aandelen van een bedrijf (verzekeraars 10\%). De bedoeling van de Amerikanen het bedrijfsleven te 'democratiseren' werd aanvankelijk in zoverre verwezenlijkt dat in $194970 \%$ van de aandelen in de handen van privé-personen was (Zielinsky \& Holloway, 1991).

Vervolgens ontstond echter een zichzelf versterkend proces waarin bedrijven de aandelen van andere bedrijven opkochten en privé-personen die graag verkochten vanwege de algemene armoede in de vroege naoorlogse jaren en vanwege de gestegen koersen. Hoe meer aandelen in de handen van bedrijven kwamen (die die niet weer verkochten) hoe hoger de prijzen stegen van de resterende aandelen, hetgeen enerzijds het accumuleren van aandelen door grote bedrijven tot een zeer winstgevende strategie maakte en anderzijds veroorzaakte dat een Japans bedrijf relatief makkelijk aan financiering kon komen omdat uitgegeven aandelen graag gekocht werden.

Bedrijven die met elkaar zaken deden (vaak fragmenten van oude Zaibatsu en van nieuwe Keiretsu) bevestigden hun lange-termijnintenties ten opzichte van elkaar door elkaars aandelen te kopen. In 1990 was dan ook bijna $75 \%$ van alle aandelen in de handen van andere bedrijven (Matsumoto, 1991). Drie redenen droegen bij aan de voor westerse begrippen uitzonderlijk hoge koers/winst-verhoudingen en daarmee uitzonderlijk lage financieringskosten. Ten eerste zorgden de voortdurende koersstijgingen ervoor dat beleggers meer naar vermogenswinst dan naar dividend keken. Ten tweede is het risico van een vijandelijke overname vrijwel nihil doordat het overgrote deel van de aandelen van een bedrijf in de handen van stabiele relaties is. 
Ten derde maakt het feit dat bedrijven, gerepresenteerd door managers, de belangrijkste aandeelhouders van andere bedrijven zijn, dat de neiging van managers om naar omzetmaximalisatie in plaats van winstmaximalisatie te streven slechts door 'gelijkgezinden' gecontroleerd wordt.

Aangemoedigd door de overheid. ongecontroleerd door de kapitaalmarkt en geholpen door goedkope financiering kunnen de grotere bedrijven omzetgroei nastreven door lange-termijninvesteringen in innovatie, kwaliteit en marktpenetratie door zorgvuldige selectie van ondergewaardeerde niches of, eventueel, dumping (Johannson \& Nonaka, 1983). Het ontbreken van effectieve controle door de kapitaalmarkt zou kunnen leiden tot X-inefficiency en algemene stagnatie maar dit wordt voorkomen door de strenge normen die de grotere bedrijven in de Keiretsu de kleinere opleggen en de discipline die voortkomt uit de hevige concurrentie tussen de verschillende Keiretsu en met buitenlandse bedrijven.

Zoals hieruit blijkt is het centrale element van het Japanse systeem dus niet samenwerkingsverbanden in brede zin, maar de specifieke langetermijnsamenwerking plus strenge controle die voorkomt in de keiretsu.

\section{Europees economisch systeem en certificatie}

Zoals hierboven reeds aangeduid hebben de Europeanen gepoogd verschillende elementen uit het Japanse systeem te imiteren in de hoop daaraan een gelijkwaardig succes te kunnen ontlenen. In eerste instantie groeide de aandacht voor kwaliteitsbewakingssystemen en werden bijvoorbeeld her en der kwaliteitskringen ingevoerd. Overheden probeerden MITI na te bootsen en een industrie- en innovatiebeleid te voeren dat expliciet gericht was op die paar sectoren waarvan men hooggespannen verwachtingen had. Met investeringsfondsen en subsidies werd geprobeerd bedrijven aan te zetten tot lange-termijninvesteringen, vooral met betrekking tot innovatie. Ook dachten overheden er goed aan te doen bedrijven aan te zetten tot meer samenwerking, ook weer met betrekking tot innovatie en projecten waarvan exportgroei verwacht werd, en het aangaan van lange-termịnrelaties. Om dit te bereiken werd met name het mededingingsrecht minder streng toegepast en werden bijvoorbeeld steeds nieuwe groepsuitzonderingen verleend van het kartelverbod van artikel 85 EEG verdrag (Jacquemin, 1991).
Of dit een heilzame weg is wordt zowel in Europa als in de Verenigde Staten door velen betwijfeld (Jorde \& Teece, 1990). De tegenstanders wijzen erop dat het toestaan van dergelijke samenwerkingsverbanden sterk concurrentieverminderend kan werken in de Europese of Amerikaanse context en daarmee op langere termijn de gezondheid van de industrie juist kan aantasten. Een van de onderliggende redeneringen is dat de op dividenden en korte-termijnwinsten beluste kapitaalmarkt in het westen maakt dat managers de samenwerkingsmogelijkheden vooral zullen benutten teneinde door concurrentievermindering en marktverdeling hun winstmarges te verhogen. Dit probleem vraagt om een andere benadering van samenwerkingsverbanden. Een voorbeeld daarvan wordt gegeven door Value Adding Partnerships waarin onafhankelijke bedrijven binnen een Porteriaanse waardeketen vergaand samenwerken (Johnston \& Lawrence, 1988).

Dit brengt ons terug bij certificatie. Een onderzoek onder 20.000 bedrijven uit 12 Europese landen toonde aan dat problemen met technische standaards en regelgeving als de belangrijkste handelsbelemmering gezien werden (Gundlach, 1991). Teneinde deze barrières te slechten werd de 'New Approach' ingevoerd. De nieuwe-aanpak richtlijnen stellen fundamentele en essentiële eisen op waarin het 'wat' centraal staat in plaats van het 'hoe'. Het vaststellen of aan de eisen wordt voldaan kan echter ook op verschillende wijzen geschieden en daardoor weer handelsbarrières met zich mee brengen. Daarom heeft de Europese Commissie vervolgens de 'Global Approach' ingevoerd. In het kader daarvan wordt overgegaan tot wederzijdse erkenning van conformiteitsbeoordelingen. De effecten hiervan worden nog eens versterkt door voor te schrijven dat zodra in het kader van certificatie Europese standaarden bereikt zijn, die ook moeten worden gebruikt. De richtlijn met betrekking tot het aanschafbeleid van bedrijven in de sectoren water, energie, transport en telecommunicatie (O.J. L297) wil voorkomen dat deze bedrijven toeleveranciers uitsluiten van het doen van een offerte door zeer specifieke eisen te stellen aan de te leveren goederen. De richtlijn bepaalt dat als een offerte verwijst nar in officiële standaarden vervatte specificaties deze offerte slechts dan afgewezen mag worden als zij aantoonbaar onvoordelig is in nauwomschreven economische zin (Heijnen \& Waszink, 1992). 
Certificatie in deze context helpt bij het tot stand brengen van de vrije interne markt. Certificatie kan ook bijdragen tot het verhogen en effectief bewaken van normen met betrekking tot veiligheid, gezondheid en milieu. Het meer centraal stellen van verbeternormen in certificaten zou al deze effecten versterken.

Belangrijker misschien dan al het voorgaande is dat certificatie het Europese bedrijven vergemakkelijkt lange-termijnrelaties aan te gaan die veel minder bedreigend zijn voor de kwaliteit van de mededinging dan het gebruik maken van uitzonderingen op artikel 85 EEG verdrag. Certificaten verschaffen extra informatie die het voor bedrijven mogelijk maakt zich in door langetermijnrelaties gecementeerde netwerken te begeven. Zij bevorderen dat 'commitments' gepleegd worden die de basis vormen van stabiele binding tussen bedrijven (Verbeke, 1989).

In het kader van deze lange-termijnrelaties (ook met banken!) is het mogelijk meer langetermijninvesteringen te doen in innovatie en kwaliteit. De stabiele netwerken maken overheidsinterventies, indien noodzakelijk geacht, eenvoudiger uit te voeren. Het algemeen invoeren van verbeternormen in certificaten geeft bedrijven in het netwerk de mogelijkheid om hun relaties aan te zetten tot grotere prestaties. De onaangetaste mededinging tussen de netwerken onderling waakt voor het uitbuiten van ongewenste machtsconcentratie. Zo zouden door het middel van certificatie, vooral met inbegrip van verbeternormen, netwerken in Europa kunnen ontstaan die dezelfde voordelen aan de Europese economie bieden als de Japanse Keiretsu. M.a.w., certificatie kan de basis vormen voor samenwerkingsverbanden die in het Europese economische systeem tot hetzelfde succesvolle resultaat kunnen leiden als de Keiretsu in het Japanse economische systeem.

Certificatie is een sterk groeiend verschijnsel. Het aanzetten tot verbeteren door middel van certificaten geschiedt nog niet op grote schaal maar lijkt aan aantrekkingskracht te winnen. In de afsluitende paragraaf worden kort een aantal voorbeelden besproken van bedrijven die actief gebruik maken van certificatie om daardoor stabiele netwerkrelaties te kunnen aangaan en deze netwerkrelaties aan te zetten tot verbetering.

\section{Voorbeelden uit de praktijk}

In de praktijk zijn duidelijke trends waarneem- baar die wijzen op het groeiend belang dat bedrijven hechten aan certificatie, zowel om de kwaliteit te bewaken als om de relaties met toeleveranciers hechter te maken. General Electric Plastics in Engeland maakte bekend dat zijn 340 toeleveranciers vanaf juni 1993 een ISO-9000 kwaliteitssysteemcertificaat dienen te hebben. Ook Motorola neemt een dergelijke stellingname in maar voegde daaraan toe dat het ISO-9000 certificaat op zich slechts een fractie is van dat waar men naar wil kijken. DSM liet weten dat medio 1994 al haar toeleveranciers ISO-9000 gecertificeerd moeten zijn. Als toevoeging hierop werd aangegeven dat ISO-9000 een belangrijke stap is op weg naar integrale kwaliteitszorg. Kennelijk hebben deze grote bedrijven behoefte aan een beter gewaarborgde kwaliteit bij hun toeleveranciers. Deze toeleveranciers worden echter nog niet actief gesteund in het komen tot integrale kwaliteitszorg.

Een meer vergaand voorbeeld wordt aangetroffen bij de Nederlandse Aardolie Maatschappij (de NAM). In 1987 werd vastgesteld dat een groot aantal leveranciers kennelijk nog te weinig waarde hechtte aan kwaliteitsborging in het algemeen en certificatie in het bijzonder. Naast aandringen op certificatie-begon de NAM ook met een evaluatie van de kwaliteitssystemen van haar toeleveranciers. De bevindingen werden op een onderling vergelijkbare manier vastgelegd in een de vorm van een 'rating'. Hierdoor trachtte de NAM zowel haar toeleveranciers bij te staan in het opzetten en verbeteren van $\mathrm{kwaliteitssystemen} \mathrm{als} \mathrm{een} \mathrm{syste-}$ matisch kader te scheppen voor zichzelf om beslissingen te nemen over toekomstige opdrachten (van 't Veer \& Waszink, 1987).

In dezelfde richting wijst de ontwikkeling, opnieuw bij de NAM, van zogenaamde "technisch potentieel metingen' als toevoeging aan ISO-9000 normen (Heijnen, 1993). Geconstateerd wordt dat kwaliteitssysteemcertificatie geen zekerheid geeft dat het eindprodukt van het voortbrengingsproces ook het gewenste doel beoogt. In een aantal gevallen is het daarom verstandig bij een toeleverancier te bepalen of deze het technisch potentieel heeft om aan de vraag te voldoen. Een methodiek is hiervoor ontwikkeld. De onderliggende gedachtengang duidt op een behoefte om de relaties met toeleveranciers anders te benaderen dan tot nu toe gebruikelijk was. Ook is duidelijk dat dergelijke potentieelmetingen een goede voorbereidende stap zijn voor het opleggen van verbeternormen. 


\section{Conclusies}

Het imiteren van elementen uit het Japanse systeem betekent niet noodzakelijkerwijs het bereiken van dezelfde resultaten. Een nadere analyse van het Japanse economische systeem laat zien dat met name de netwerkverbanden en de daarin verwerkte noodzaak tot verbetering en (steeds) grotere prestaties een grote bijdrage leverden aan het Japanse succes. Een gelijksoortig systeem, meer op de Europese situatie toegespitst, kan ontstaan op basis van certificatie.

Certificaten verschaffen informatie, en daarmee transparantie, in de markt. Daarnaast kan de voldoende mate van vertrouwen omgezet worden in lange-termijnrelaties.

Dit zou ook in Europa verwezenlijkt kunnen worden door het op grotere schaal gebruikmaken van certificatie en vooral door het introduceren van certificaten met verbeternormen. Een aantal grotere bedrijven hebben al stappen gezet in die richting. Het mag duidelijk zijn dat certificatie op zichzelf gesteld nog geen garantie voor succes oplevert. Enerzijds zijn de welvaartseffecten van ook het meest efficiente netwerk mede afhankelijk van andere factoren, zoals bijvoorbeeld de ontwikkeling van de vraag of universiteit-industrierelaties. Anderzijds behoort de kwaliteit van het certificatieproces zelf gewaarborgd te blijven. Als certificatie zou vervallen tot een verbureaucratiseerd 'even-een-papiertje-halen', zullen ook de positieve effecten op netwerkvorming uitblijven.

De argumenten in dit artikel mogen echter zowel het bedrijfsleven als de overheid redenen hebben gegeven certificatie niet slechts als een instrument van kwaliteitsborging te beschouwen maar ook als een middel om tot waardevolle netwerkvorming te komen.

\section{I T E R A T U U R}

Asanuma, B., (1989), 'Manufacturer-Supplier Relations and the Concept of Relation-Specific Skill', Journal of the Japanese and International Economies, Vol 3 (March), pp. 1-30.

Bij, J.D. van der, (1992), 'Certificering en de Structuur van Kwaliteitssystemen', Bedriffskunde, Vol.2, pp.188-193.

Cutts, R.L., (1992), 'Capitalism in Japan: Cartels and Keiretsu' Harvard Business Review, July-August, pp.48-55.
Gundlach, H.C.W., (1991), The Role of Accreditation and the Route to the CE Mark, Raad voor de Certificatie, Driebergen, 1991.

Heijnen, W.H.P.M., (1993), 'Technisch potentieel meting als extra dimensie op ISO-9000-normen', SIGMA, Nr.3, pp.2-6.

Heijnen, W.H.P.M. \& Waszink, A.C., (1992), A view on International Standardisation in the Oil and Cas Business, International Organisation for Standardisation (ISO)/ Technical Commitee (TC) 67, progress paper, june 1992.

Imai, K., (1989), 'Evolution of Japan's Corporate and Industrial Networks' in B. Carlson (ed.) Industrial Dynamics, Dordrecht, Kluwer Academic, pp.123-156.

Jacquemin, A., (1991), 'Cooperation in Research and Development and European Competition Policy', in P de Wolf (ed.) Competition in Europe, Dordrecht, Kluwer Academic, pp.209-227.

Johansson, J.H. \& Nonaka, I., (1983), 'Japanese Export Marketing: Structures, Strategies, Counterstrategies', International Marketing Review, Winter, pp.13-25.

Johnston, R. \& Lawrence, P.R., (1988), 'Beyond Vertical Integration: The Rise of the Value-Adding Partnership', Harvard Business Review, july-august, pp.94-101.

Jorde, T.M. \& Teece, D.J., (1990), 'Innovation and Cooperation: Implications for Competition and Antitrust', Journal of Economic Perspectives, Vol.4, No.3, pp.75-96.

Matsumoto, K., (1991), The Rise of the Japanese Corporate System, London/New York, Kegan Paul International.

Rapp, V., (1992), 'Japanese Multinationals: an Evolutionary Theory', in T. Leuenberger \& M.E. Weinstein (eds.) Europe, Japan and America in the 1990's: Cooperation and Competition, Berlin/Heidelberg, Springer Verlag, pp.221-267.

Turnbull, P; Oliver, N. \& Wilkinson, B., (1992), 'Buyer-Supplier Relations in the UK Automotive Industry: Strategic Implications of the Japanese Manufacturing Model', Strategic Management Journal, Vol.13, pp.159-168.

Veer, M.G. van het \& Waszink, A.C., (1987), Kwaliteitssysteem-evaluatie van leveranciers door NAM, Sigma, Nr.3, pp.20-24.

Verbeke, W.J.M., (1989), 'Relatievorming tussen bedrijven', Bedriifskunde, Vol.1, pp.61-70.

Wijnberg, N.M., (1994), 'The National System of Innovation: Selection Environments and Selection Processes', Technology in Society, Vol.16, No.3, pp.313-320.

Wolferen, K. van, (1989), The Enigma of Japanese Power, London, MacMillan.

Zielinsky, R. \& Holloway, N., (1991), Unequal Equities: Power and Risk in Japan's Stock Market, Kodanska International, Tokyo/New York. 